\title{
A Review Paper on Brain Tumor Segmentation and Detection
}

\author{
Ms. Priya Patil ${ }^{1}$, Ms. Seema Pawar ${ }^{2}$, Ms. Sunayna Patil ${ }^{3}$, Prof. Arjun Nichal ${ }^{4}$ \\ BE Students, Electronics \& Telecommunication Engineering, AITRC, Vita, India ${ }^{1,2,3}$ \\ Assistant Professor, Electronics \& Telecommunication Engineering, AITRC, Vita, India ${ }^{4}$
}

\begin{abstract}
For study of brain tumor detection and segmentation the MRI Images is very useful in recent years. Due to MRI Images we can detect the brain tumor. For detection of unusual growth of tissues and blocks of blood in nervous system can be seen in an MRI Images. The first step of detection of brain tumor is to check the symmetric and asymmetric Shape of brain which will define the abnormality. After this step the next step is segmentation which is based on two techniques 1) F-Transform (Fuzzy Transform) 2) Morphological operation. These two techniques are used to design the image in MRI. Now by this help of design we can detect the boundaries of brain tumor and calculate the actual area of tumor. In this the f-transform is used to give the certain information like rebuilt of missing edges and extracting the silent edges. Accuracy and clarity in an MRI Images is dependent on each other.
\end{abstract}

Keywords: Brain Tumor, MRI Images, Fuzzy Transform, Morphological operation.

\section{INTRODUCTION}

Now days the MR Images are very useful in a Medical field like Medical image processing. The brain tumor defines the unusual growth of tissues and uncontrolled cells proliferation so due to this the natural pattern of cell growth and death is failed. The brain tumor is of two stages:-

1) Primary stage

2) Secondary stage.

When tumor spread in any part of brain then it is known as brain tumor. Now when brain tumor can identified number of symptoms including seizures, mood changing, difficulty in walking and hearing, vision, and muscular movement etc. brain tumor is classified into Gliomas, medulloblastoma, epeldymomas, CNS lymphoma and oligodendrogloma.

In primary stage the tumor can be removed but in secondary stage, the tumor disease spread, due to this after removal of tumor the seldom remains and grow back again so this is the biggest problem in the secondary stage of tumor .

Why this problem occurs? It occurs due to inaccurately location of area of tumor. The next step is detection techniques. In this the any segmentation and detection are to measure detection techniques the imaging of brain tumor can be done by-

1) MRI scanning that is magnetic resonant image

2) CT scanning i.e. computer tomography

3) Ultra sound etc.

There are several method to detect an brain tumor by that the tumor method we can diagnose and detect more easily .some edges are nuclear network algorithm watershed and edge detection, fuzzy c mean algorithm, asymmetry of brain is used to detect an abnormality .
The problem of edge detection is the one of the most attractive problem for the image processing due to this it's various applications.

Candy-edge detection is the one of the most useful feature in image segmentation. In this candy-edge detection is used for extraction of edges. F-transform is an intelligent method to handle uncertain information. This is useful for detection of tumor boundaries. It is very easy method for detection is a promising and efficient method for future and edge extraction progress.

\section{BASIC METHODOLOGY}

Fig 1 shows the basic block diagram of brain tumor detection and segmentation. MRI images of brain are taken for processing.

Image Acquisition: First considered that the MRI scan images of a given patient are either color, Gray-scale or intensity images herein are displayed with a default size of $220 \times 220$. If it is color image, a Gray-scale converted image is defined by using a large matrix whose entries are numerical values between 0 and 255 , where 0 corresponds to black and 255 white for instance. Then the brain tumor detection of a given patient consist of two main stages namely, image segmentation and edge detection.

Pre-processing stage: Pre-processing stage consists of Noise removal this can be done by using various spatial filters linear or nonlinear filters (Median filter). Other artifacts like text removed by some morphological operations.

RGB to grey conversion and reshaping also takes place here. It includes median filter for noise removal. The 
possibilities of arrival of noise in modern MRI scan are very less. It may arrived due to thermal Effect.

Image Smoothing: It is the action of simplifying an image while preserving important information. The goal is to reduce noise or useless details without introducing too much distortion so as to simplify subsequent analysis.

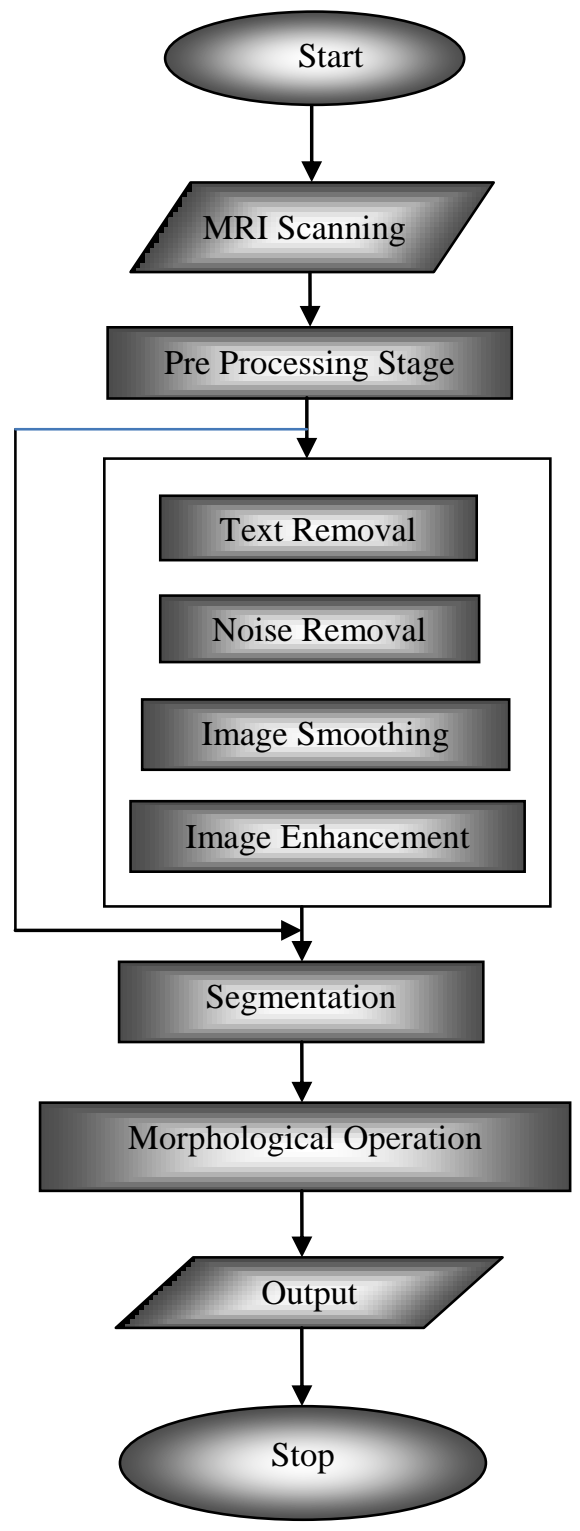

Fig. 1. Basic Block diagram of brain tumor detection and segmentation

Image Registration: Image registration is the process of bringing two or more images into spatial correspondence (aligning them). In the context of medical imaging, image registration allows for the concurrent use of images taken with different modalities (e.g. MRI and CT), at different times or with different patient positions. In surgery, for example, images are acquired before (preoperative), as well as during (intra-operative) surgery. Because of time constraints, the real-time intraoperative images have a lower resolution than the pre-operative images obtained before surgery. Moreover, deformations which occur naturally during surgery make it difficult to relate the highresolution pre-operative image to the lowresolution intra-operative anatomy of the patient. Image registration attempts to help the surgeon relate the two sets of images [8].

Image Segmentation: The segmentation is the most important stage for analysing image properly since it affects the accuracy of the subsequent steps. However, proper segmentation is difficult because of the great verities of the lesion shapes, sizes, and colors along with different skin types and textures. In addition, some lesions have irregular boundaries and in some cases there is smooth transition between the lesion and the skin. To address this problem, several algorithms have been proposed. They can be broadly classified as thresholding, edge-based or region-based, supervised and unsupervised classification techniques

- Threshold segmentation

- Water shed segmentation

- Gradient Vector Flow (GVF)

- K-mean Clustering

- Fuzzy C-means Clustering

Morphological Operations: after segmentation morphological processing is applied to remove unwanted part. It consists of image opening, image closing, dilation, erosion operations.

At the end the decision has taken weather that MRI image consists of any tumor or not and weather it normal or abnormal.

\section{REVIEW OF THE DIFFERENT PAPERS}

The 2016 WHO i.e. world health organization on classification of tumor of central nervous system is an conceptutional as well as pertain overview of predecessor the WHO classification CNS tumor which is used molecular parameters for its diagnosis structure. Further than 2016 CNS WHO presence the new diffuse glomas and other tumor and defines the new feature like both histology as well as molecule [1].

The fourth edition of the WHO i.e. world health organization classification of tumor of central nervous system published in 2007.there are several new titles and information list including glioma, papillary, glioneuronal tumor etc. the histological variants are capable of different edge distribution, location, symptoms and the behaviours or clinical [2].

Fuzzy clustering is method which widely used biomedical to detect the image. The effective fuzzy clustering algorithm is used in abnormal MR brain image 
segmentation. By using clustering in brain tumor It is a new technique of detection of brain tumor and for segmentation we can diagnose accurately the region of very good result and accuracy. The watershed method is cancer.to provides better identification of brain tumor combined with edge detection operation. The color brain magnetic resonant images is applied [3]. MRI images can be obtained by this algorithm. In this the RGB image is converts into on HSV color image so that

Now a day's brain tumor is one of the most hazards diseases so its detection should be fast and accurate. It can be achieved by automated tumor detection techniques on medical images and one of the automated tumor detection techniques is MRI images .which defines the tumor growth region and the edges detection. As compare to other techniques with this is gives more accurate as well as clear and advantages of automated tumor detection techniques is used for removal of tumor if needed [4].

The neural networks is a new technology has been discovered the neural network are an "HOT" research area, like a cardiology, radiology, oncology etc.to solve highly complex problem three is combination of neurons into layers permits for artificial neural network. In an medical applications the neural network are like ANNs etc. and the medical application the neural network are used to map an input into a desired output [5]. the image is separated in 3 regions which are known as hue, saturation and intensity. The canny edge detector is applied is applied to an output image for rebuilt process of edge occurs in this .at last combining the three images and the final resultant brain tumor segmented image is obtained. This algorithm is applied on 20 brain MRI images for excellent result [6].

In an MRI image the highly irregular boundaries of tumor tissues is seen. For a segmentation of medical image, the deformable modes and region base methods are used. The main problems are there in MRI images like undefined location of tumor are unseen boundaries or data loss at boundaries and a silent edge not extended. By using this algorithm the silent edge is extended and found boundary of tumor location or area and once the boundary or location of tumor is seen clearly. Then removal of tumor can be take place [7].

\section{TABLE I COMPARISON OF REVIEW PAPER}

\begin{tabular}{|c|c|c|c|c|}
\hline Author & Year & Paper Name & Technique & Result \\
\hline P. Kleihues & 1993 & $\begin{array}{l}\text { The new WHO classification } \\
\text { of brain tumors }\end{array}$ & Brain Pathology & $\begin{array}{l}\text { It gives different edge } \\
\text { distribution, Syptoes. }\end{array}$ \\
\hline D. N. Louis & 2007 & $\begin{array}{l}\text { The } 2007 \text { WHO classification } \\
\text { of tumors of the } \\
\text { central nervous system }\end{array}$ & $\begin{array}{c}\text { Detection of } \\
\text { CNS(Central Nervous } \\
\text { System) } \\
\end{array}$ & $\begin{array}{l}\text { The molecular parameter is } \\
\text { used for its diagnosis } \\
\text { structure. }\end{array}$ \\
\hline $\begin{array}{c}\text { D. J. } \\
\text { Hemanth }\end{array}$ & 2009 & $\begin{array}{l}\text { "Effective Fuzzy Clustering } \\
\text { Algorithm for } \\
\text { Abnormal MR Brain Image } \\
\text { Segmentation }\end{array}$ & $\begin{array}{l}\text { Abnormal MR Brain } \\
\text { Image Segmentation }\end{array}$ & $\begin{array}{l}\text { It gives abnormal MR brain } \\
\text { image segmentation } \\
\text { accurate region of cancer } \\
\text { and better identification of } \\
\text { branch i.e. stage of cancer. }\end{array}$ \\
\hline $\begin{array}{l}\text { A. A. } \\
\text { Abdullah }\end{array}$ & 2012 & $\begin{array}{l}\text { Implementation of an } \\
\text { improved cellular neural } \\
\text { network algorithm for brain } \\
\text { tumor detection }\end{array}$ & Neural network & $\begin{array}{l}\text { It solves high complex } \\
\text { problem and it is used to } \\
\text { map an input into a desired } \\
\text { output. }\end{array}$ \\
\hline $\begin{array}{l}\text { I. Maiti and } \\
\text { M. } \\
\text { Chakraborty }\end{array}$ & 2012 & $\begin{array}{l}\text { A new method for brain tumor } \\
\text { segmentation based on } \\
\text { watershed and edge detection } \\
\text { algorithms in HSV } \\
\text { color model }\end{array}$ & $\begin{array}{c}\text { watershed and edge } \\
\text { detection algorithms in } \\
\text { HSV } \\
\text { color model }\end{array}$ & $\begin{array}{l}\text { It gives color brain MRI } \\
\text { image foe very good } \\
\text { accuracy result. }\end{array}$ \\
\hline $\begin{array}{l}\text { S. Charutha } \\
\text { and M. J. } \\
\text { Jayashree }\end{array}$ & 2014 & $\begin{array}{l}\text { An efficient brain tumor } \\
\text { detection byintegrating } \\
\text { modified texture based region } \\
\text { growing and cellular automata } \\
\text { edge detection }\end{array}$ & $\begin{array}{l}\text { Automated and } \\
\text { efficient brain tumor } \\
\text { detection }\end{array}$ & $\begin{array}{l}\text { The proposed method } \\
\text { efficient in treatment of } \\
\text { brain tumor and also in } \\
\text { removal of tumor. }\end{array}$ \\
\hline $\begin{array}{l}\text { R. Preetha } \\
\text { and G. R. } \\
\text { Suresh }\end{array}$ & 2014 & $\begin{array}{l}\text { Performance Analysis of Fuzzy } \\
\text { C Means } \\
\text { Algorithm in Automated } \\
\text { Detection of Brain Tumor }\end{array}$ & $\begin{array}{l}\text { Fuzzy C Means } \\
\text { Algorithm in } \\
\text { Automated Detection } \\
\text { of Brain Tumor }\end{array}$ & $\begin{array}{l}\text { The boundary of tissues can } \\
\text { be seen clearly. }\end{array}$ \\
\hline
\end{tabular}




\section{IJIREEICE \\ International Journal of Innovative Research in Electrical, Electronics, Instrumentation and Control Engineering \\ ISO 3297:2007 Certified \\ Vol. 5, Issue 1, January 2017}

\section{CONCLUSION}

In this paper, we have proposed different techniques to detect and segment Brain tumor from MRI images. To extract and segment the tumor we used different techniques such as SOM Clustering, k-mean clustering, Fuzzy C-mean technique, curvelet transform. It can be seen that detection of Brain tumor from MRI images is done by various methods, also in future work different automatic methods achieve more accuracy and more efficient.

\section{REFERENCES}

[1] D.N.Louis, et al,"The $2007 \mathrm{WHO}$ classification of tumor of central nervous system,"Actdneuropathological, vol114, pp 97-109'2007.

[2] P.Kleihues, et al."The new WHO classification of brain tumor, "brain pathology, vot3, pp255-268, 1993.

[3] D.J.Hemanth, et al,"effective fuzzy clustering algorithm for abnormal MR brain image segmentation," in advance computing conference 2009.IACC 2009.IEEE international, 2009, pp-609-614.

[4] S.chrutha and M.J.Jayashree, "An efficient brain tumor detection by integrating modified texture based region growing and cellular automata edge detection, " in Control Instrumentation, Communication and Computational Technology (ICCICCT),2014 International Conference On,2014,pp.1193-1199.

[5] A. Abdullah, et al., "Implementation of an improved cellular neural network algorithm for brain tumor detection," in Biomedical Engineering(Isobel), 2012 International Conference on, 2012, pp. 611- 615 .

[6] I. Maiti and M. Chakra borty, "A new method for brain tumor segmentation based on watershed and edge detection algorithms in HSV color model," in Computing and Communication Systems (NCCCS), 2012 National Conference on, 2012, pp. 1-5.

[7] R. Preetha and G. R. Suresh, "Performance Analysis of Fuzzy C Means Algorithm in Automated Detection of Brain Tumor," in Computing and Communication Technologies (WCCCT), 2014 World Congress on, 2014, pp. 30-33.

[8] Bandana Sharma et al. "Review Paper on Brain Tumor Detection Using Pattern Recognition Techniques" published in International Journal of Recent Research Aspects ISSN: 2349-7688, Vol. 3, Issue 2, June 2016, pp. 151-156

\section{BIOGRAPHIES}

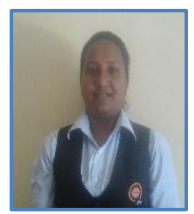

Ms. Priya Patil Pursuing her BE in Electronics \& Telecommunication from AITRC vita. Her area of interest is Image Processing and Embedded system.

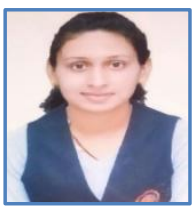

Ms. Seema Pawar Pursuing her BE in Electronics \& Telecommunication from AITRC vita. Her area of interest is Image Processing and Embedded system.

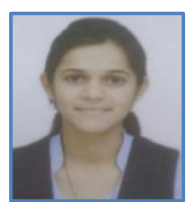

Ms. Sunayna Patil Pursuing her BE in Electronics \& Telecommunication from AITRC vita. Her area of interest is Image Processing and Embedded system.

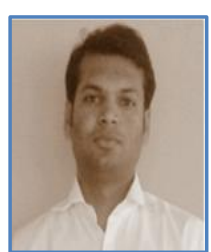

Prof. Arjun Nichal Received his M. Tech degree from Walchand college of Engg, Sangli in 2012. Pursuing Ph.D. from Shivaji University Kolhapur. Working as a assistant professor in AITRC vita. His area of interest is image processing, embedded system. Published one E- book and 17 international journal papers 